Etnográfica

Revista do Centro em Rede de Investigação em

Antropologia

vol. $15(1) \mid 2011$

Vol. $15(1)$

\title{
¿Actuar la brasileñidad? Tránsitos a partir del mercado del sexo
}

Performing Brazilianness? Displacements from the sex market

\section{Adriana Piscitelli}

\section{(2) OpenEdition}

\section{Journals}

Edición electrónica

URL: https://journals.openedition.org/etnografica/765

DOI: 10.4000/etnografica.765

ISSN: 2182-2891

\section{Editor}

Centro em Rede de Investigação em Antropologia

\section{Edición impresa}

Fecha de publicación: 1 febrero 2011

Paginación: 5-29

ISSN: 0873-6561

\section{Referencia electrónica}

Adriana Piscitelli, «iActuar la brasileñidad? Tránsitos a partir del mercado del sexo», Etnográfica [En línea], vol. 15 (1) | 2011, Publicado el 23 octubre 2011, consultado el 10 febrero 2022. URL: http:// journals.openedition.org/etnografica/765 ; DOI: https://doi.org/10.4000/etnografica.765

\section{(c) (7) \&}

Etnográfica is licensed under a Creative Commons Attribution-NonCommercial 4.0 International License. 


\section{¿Actuar la brasileñidad? Tránsitos a partir del mercado del sexo ${ }^{1}$}

\section{Adriana Piscitelli}

En este texto considero las nociones de brasileñidad que permean los espacios de agencia de brasileñas que migraron a Europa a partir de diferentes sectores del mercado del sexo. El análisis está basado en una etnografía multi-situada realizada en Brasil, Italia y España. Considero cómo la alteración de contextos incide en la re-significación de las diferenciaciones que permean su incorporación en los mercados del sexo y del casamiento en esos países del Sur de Europa. Reflexiono sobre esos aspectos explorando cómo construcciones de género, nacionalidad, etnicidad, y "raza" son accionadas en las interacciones de esas migrantes. Finalmente, trazo relaciones entre las categorías de identidad recreadas, los contextos migratorios y las transformaciones en los significados concedidos al consumo de sexo en el mercado global del sexo contemporáneo.

PALABRAS-CLAVE: mercado del sexo, mercado matrimonial, migración, género, sexualidad, etnicidad.

\section{EN ESTE TEXTO CONSIDERO LAS NOCIONES DE BRASILENIIDAD ${ }^{2}$ accionadas por mujeres que migraron a países del Sur de Europa a partir de diferentes sectores del mercado del sexo y continuaron trabajando en él o lo abandonaron al casarse en los países de destino. Me refiero al mercado del}

l Este texto está basado en investigaciones apoyadas por la Fundación Guggenheim, y por las agencias de fomento brasileñas CAPES, CNPq y FAPESP. Agradezco el apoyo, material bibliográfico y contactos a Luisa Leonini, Mônica Schpun, Giovanna Campani, a los funcionarios de la Universitá degli Studi di Milano, de los Consulados de Brasil en Milán, Barcelona y Madrid, particularmente a Gelson Fonseca, Dolores Juliano, Verena Stolcke, Isabel Holgado, Bea, Constancia, Carla, Justine, Cristina Garaizábal, Lurdes Perramon, Beatriz Espejo, Elena, Estefanía Acién, y demás integrantes de los grupos Licit, Genera, Ambit Dona, Hetaira, del proyecto Carretera en Calella, Coletivo de Transexuales de Cataluña, Asociación pro Derechos Humanos de Andalucía, a Laura Agustín y a los integrantes de la red Industria del Sexo. Agradezco también el apoyo de Durval Ferraz, Marco Aurélio Garcia y Cristina Bellelli y las sugestiones de Kamala Kempadoo, Mariza Corrêa y Ana Fonseca.

2 Me refiero a los trazos "étnicos" asociados al Brasil. 
sexo considerando el juego de oferta y demanda en el que se intercambia sexo por dinero o por otros beneficios económicos, incluyendo la prostitución, pero sin reducirse a ella. El análisis está basado en una etnografía multi-situada (Clifford 1997) realizada entre 2000 y 2009 en diversos lugares, en Brasil, Italia y España.

Mi interés es analizar cómo la alteración de contextos incide en la re-significación de las marcas de identidad. Reflexiono sobre este aspecto explorando cómo nociones de género, sexualidad, nacionalidad y "raza" son activadas en las interacciones de esas migrantes. Mi argumento principal es que la creación de espacios de agencia de esas mujeres está permeada por la re-creación de esas categorías, reconfiguradas en función de los contextos migratorios y de los lugares ocupados en ellos. Desarrollo esas ideas dialogando con dos líneas de debate: la discusión sobre la circulación de categorías de identidad a través de las fronteras y las reflexiones sobre la mercantilización de la intimidad.

En las primeras partes del texto describo el trabajo de campo y considero las ideas presentes en las líneas de debate mencionadas. Analizo después las categorías de identidad afirmadas en los procesos migratorios. Finalmente, comento cómo los atributos de brasileñidad accionados por esas migrantes mantienen relaciones con las especificidades de los contextos migratorios, con los significados concedidos al consumo de sexo en el mercado global del sexo contemporáneo y con las articulaciones y tensiones entre ese mercado y el matrimonial.

\section{ETNOGRAFÍA}

Para aprehender la relación entre los desplazamientos de brasileñas en el mercado trasnacional del sexo, la circulación de significados culturales y la re-creación de marcas de identidad, opté por la estrategia de "seguir a las personas" (Marcus 1995). Acompañar esas mujeres me condujo a lugares diferentes y a observar distintos tipos de tránsitos.

En 2000 inicié una etnografía en los circuitos de "turismo sexual" ${ }^{3}$ heterosexual en Fortaleza, una de las principales ciudades asociadas a ese tema, en el Nordeste del Brasil. ${ }^{4}$ Se trata de una ciudad con más de 2 millones de

3 Utilizo esa expresión entre comillas, considerando las problematizaciones de las que es objeto en la producción académica que muestra como varios presupuestos inicialmente asociados a esa noción no se sustentan: la heterosexualidad, la idea de que involucra básicamente hombres del Primer Mundo que viajan a los países en desarrollo en busca de placeres sexuales no disponibles en sus países y su identificación exclusivamente con la idea de prostitución.

4 El trabajo realizado en Fortaleza tuvo una duración total de doce meses y se desarrolló en diferentes momentos entre 2000 y 2008. Realicé observaciones y entrevistas en profundidad con noventa y cinco personas, incluyendo mujeres y hombres nativos/as que se relacionan sexualmente con visitantes extranjeros/as, hombres y mujeres extranjeros/as que se relacionan con nativos/as y agentes vinculados al turismo y a la prostitución en la ciudad. 
habitantes, con una de las regiones metropolitanas más pobres del país, conocida por sus bellas playas y por su agitada vida nocturna. En Fortaleza, los circuitos turísticos asociados al consumo de sexo están atravesados por un "clima" transnacional, del que forman parte las relaciones que las chicas locales establecen con sus "novios"/clientes foráneos. Mientras realizaba el trabajo de campo percibí que el intenso contacto de esas chicas con turistas extranjeros y con mujeres "de la tierra" que habían migrado y regresaban periódicamente a la ciudad estimulaba sus deseos de viajar al exterior. Y ese anhelo se materializaba con cierta frecuencia mediante invitaciones de turistas extranjeros (Piscitelli 2007).

Entre las mujeres que entrevisté, la mayor parte viajaba con destino al Norte de Italia. Seguí sus itinerarios en ese país durante dos meses, en 2004, y por varias semanas, entre 2005 y 2007, en Fortaleza, donde las reencontré en momentos de vacaciones en el Brasil (Piscitelli 2008b). En el desplazamiento a Europa, la mayoría dejó el mercado del sexo, casándose con italianos. ${ }^{5}$ Las entrevistas fueron realizadas en diversos barrios de Milán y en ciudades próximas, Abbiategrasso y Voghera, y también en Verona.

Durante la primera mitad de la década de 2000, sin embargo, España fue considerada como uno de los principales países europeos destino de brasileñas que migraban a partir del mercado del sexo. Interesada en ampliar la perspectiva a partir de la cual comprender la re-creación de categorías de identidad, realicé nueve meses de trabajo de campo en ese país, entre 2004 y 2009, en Barcelona, Madrid, Bilbao y Granada. Las brasileñas que entrevisté trabajaban en diversos sectores del mercado del sexo en Brasil, incluyendo el "turismo sexual”, y la mayoría continuó haciéndolo en ese país (Piscitelli 2009). ${ }^{6}$

5 En Italia los datos fueron obtenidos a través de observación y entrevistas en profundidad realizadas con catorce brasileñas, ocho que migraron desde Fortaleza, cuatro desde otros lugares y dos que hacían tránsitos estacionales entre Milán y Fortaleza. Del conjunto de mujeres que migraron de Fortaleza, la mitad formó parte de mi universo de entrevistadas en la investigación ejecutada en esa ciudad y las demás integraban sus redes de relaciones. También fueron entrevistados siete italianos, de los cuales cinco eran maridos y dos "novios/clientes" de esas entrevistadas. Parte significativa del trabajo consistió en acompañar la cotidianeidad de las personas, en sus casas y sitios de trabajo, salidas nocturnas y fiestas de amigos y de familia. La investigación incluyó también entrevistas con ocho personas clave relacionadas con organizaciones no-gubernamentales dedicadas a trabajar con prostitución y tráfico de personas y con representantes del Consulado Brasileño de Milán, así como la recolección de fuentes secundarias.

6 El trabajo de campo incluyó observación en entidades que apoyan a trabajadoras/es del sexo, en espacios destinados a la oferta de esos servicios en la calle, pisos y clubes; entrevistas en profundidad con dieciséis mujeres y cinco travestis brasileñas, la mayor parte trabajadoras del sexo, con cinco clientes españoles y cuatro propietarias/os de establecimientos destinados a la prostitución. Esas entrevistas fueron realizadas en pisos en los que se ofrecen servicios sexuales, cafés y bares "étnicos" brasileños y en sus propias casas. También fueron realizadas entrevistas en profundidad con veintiocho agentes vinculados a diversas entidades de apoyo a migrantes y/o a trabajadoras del sexo, funcionarios de los Consulados de Brasil en Barcelona y en Madrid, al representante legal de la Asociación [continua] 
Sintetizando, todas las entrevistadas partieron de contextos del mercado del sexo en Brasil, pero como la mayoría de las que migró a Italia lo abandonó a través del casamiento, las que se dirigieron a España predominantemente permanecieron en él, inclusive las que se casaron o convivieron con españoles. Así, en el proceso de "seguir a las personas" acompañé los caminos seguidos por esas brasileñas en diferentes ciudades y países, en espacios de trabajo dentro y fuera del mercado del sexo y en diferentes escenarios de sociabilidad. Y consideré cómo los trazos asociados a la brasileñidad eran re-significados en el ámbito de las relaciones conyugales/amorosas y también de las relaciones sexuales comerciales.

Esta yuxtaposición de lugares y relaciones puede parecer un escándalo metodológico, provocando la impresión de que estoy intentando crear una continuidad etnográfica que atraviesa contextos, lugares e "instituciones", casamiento y prostitución. Lejos de esa pretensión, mi intención fue acompañar las activaciones y re-significaciones de marcas de identidad en esas disyunciones. A través de ese procedimiento establecí conexiones entre los diferentes sitios y ámbitos en los que fue realizado el trabajo.

Inicié la etnografía a partir de mi posicionamiento como feminista, radical en el inicio de la investigación, imaginando que las brasileñas insertas en el mercado transnacional del sexo eran mujeres muy jóvenes, en situación de extrema subordinación frente a hombres de países "ricos" que las explotaban en la prostitución. Me introduje en ese universo portando los diversos privilegios que me conferían mi clase social, nivel de educación, inserción profesional como investigadora de una prestigiosa universidad, mi "color", considerado blanco en Brasil, y en algún grado el hecho de ser extranjera en un lugar en el que ser "de afuera", aunque se trate de un país vecino, concede algún prestigio. Durante la inmersión en el campo, mis ideas se fueron modificando.

La diversidad de relaciones que involucraban intercambios sexuales y económicos me condujo a percibir la imposibilidad de fundir mercado del sexo y prostitución. Algunas entrevistadas ofrecían servicios sexuales en lugares en los que el mercado del sexo tenía sectores altamente organizados, que se adecuan a la noción de industria del sexo. ${ }^{7}$ Otras, intercambiando sexo por regalos, pasajes de avión y otros beneficios materiales, establecían relaciones que se aproximan a la idea de sexo transaccional, que pueden ser pensadas como sexo comercial en términos analíticos, pero no son consideradas como prostitución por las personas involucradas (Hunter 2002; Kempadoo 2004).

[continuação] Nacional de Clubes de Alterne (ANELA), en Barcelona, y a funcionarios de la Comisaría de Extranjería. La investigación incluyó también el análisis de fuentes y de material secundario y de una página web española destinada a clientes de prostitutas.

7 Pensada como la organización de emprendimientos destinados al sexo comercial, aglutinando propietarios, gerentes y trabajadores/as (Weitzer 2000). 
La confrontación con las percepciones de mis entrevistadas, para las que la explotación de la que frecuentemente son objeto es comercial y no sexual, me condujo a problematizar las bases teóricas en las que se apoya la noción de explotación sexual. La idea de la extrema juventud de esas mujeres también fue desafiada, particularmente por algunas que fueron a trabajar como prostitutas en España. En ese proceso, la dicotomía entre mujeres del "Tercer Mundo" victimizadas y hombres del "Primer Mundo" que ocupaban el lugar de verdugos, dio lugar a un cuadro complejo de distribuciones diferenciadas de poder, en el que era posible percibir diversas dimensiones de agencia.

Ese proceso también está asociado al desplazamiento de mi posición como investigadora. Marcus (1995) observa que en el tránsito entre "paisajes" diferentes, la identidad del antropólogo es re-negociada. En mi circulación entre diversos sitios, mis privilegios se desdibujaban. En esos países del Sur de Europa, mis entrevistadas percibían ese desplazamiento y me veían como compartiendo con ellas una posición frágil, sin pasaporte europeo y racializada como latinoamericana. La fragilidad se agravaba en mi caso, debido a mi escaso conocimiento de los lugares por los que transitaba y de sus peligros y por mi relativa "pobreza", ya que mis becas de investigación eran de valores menores a los que la mayoría de esas mujeres recibía por su trabajo. Desde posiciones que consideraban contextualmente "superiores", me protegían. Y esa protección, que evocaba alguna idea de poder, me estimuló a reflexionar sobre la constitución de sus espacios de agencia fuera del Brasil.

\section{MERCADO DEL SEXO Y MERCADO MATRIMONIAL}

En los últimos años, diversas lecturas socio-antropológicas han demostrado la interpenetración entre prácticas económicas y relaciones afectivas o/y sexuales en el ámbito de la intimidad. Me refiero al ámbito que abriga relaciones física y/o emocionalmente próximas, predominantemente vinculadas al sexo, al amor o al cuidado. De acuerdo con esas perspectivas, esa interpenetración adquiere matices particulares en el momento actual, en el que se intensifica progresivamente la idea de que las relaciones íntimas pueden ser compradas o vendidas (Constable 2009; Hochshild 2003; Zelizer 2009). Las relaciones íntimas no necesariamente forman parte de la esfera doméstica, ya que se pueden comprar o vender servicios de cuidado y sexuales fuera de ella, en escuelas, hospitales y burdeles. Constable (2009) afirma que, a pesar de ello, en esta fase de singular mercantilización, los discursos sobre la intimidad continúan entrelazándose con nociones de género y domesticidad y, lo que parece paradójico, con la idea de dádiva, como algo que se opone al mercado.

Cuando inicié la etnografía, no imaginé que un trabajo centrado en el mercado del sexo me condujese a considerar sus relaciones y tensiones con el mercado matrimonial. Me refiero a articulaciones que involucran aspectos 
vinculados a la intimidad, pero que van más allá de eso. El trabajo de campo mostraba que consumidores de sexo europeos escogían brasileñas como esposas en diferentes lugares del mercado transnacional del sexo, en el ámbito del "turismo sexual" en Brasil y también en espacios de prostitución en España.

Treinta años atrás, siguiendo líneas análogas a las formulaciones de Bourdieu sobre estrategias matrimoniales, Alain Desroisières (1978) delineaba distinciones entre ambos mercados. De acuerdo con el autor, ellos no son independientes, pero tampoco coinciden. Las relaciones situadas en el mercado del sexo son externas al casamiento. Regidas por la libido y por relaciones interpersonales, siguen leyes diferentes a las que rigen el casamiento. Este último es la forma jurídica de un tipo de relación que, socialmente aprobada, se aleja de la idea de transgresión, constitutiva del mercado del sexo. Y, en un marco en el que la acumulación de capital material y simbólico posibilita el acceso masculino a la sexualidad de un número mayor de mujeres, para los hombres de clases populares, con recursos económicos y sociales inferiores, el casamiento se impone como única vía de acceso a la sexualidad femenina.

Esas formulaciones fueron elaboradas tomando como referencia la sociedad francesa de la década de 1970, que aparece como cerrada y marcada sobre todo por diferencias entre clases sociales. Pero en la década del 2000, en el marco de la transnacionalización de los dos mercados, las fronteras entre ellos parecen desdibujarse en lo que se refiere a la elección del cónyuge.

Esa disolución no es banal pues incide en la irrupción de la transgresión en el ámbito del mercado matrimonial. Me refiero al desafío a normas homogámicas y "homocromáticas", cuando el casamiento une personas en situaciones desiguales en términos del posicionamiento estructural de sus países de origen, de clase social y de acceso a la documentación, que son afectadas por procesos diferenciados de racialización, de los que forma parte una intensa erotización de las personas situadas en posición inferior.

Cabe preguntarse, entonces, sobre los matices particulares adquiridos por las reconfiguraciones identitarias en experiencias diferenciadas de intimidad, en el tránsito entre espacios y también en el desplazamiento entre esos mercados.

\section{MARCAS DE IDENTIDAD A TRAVÉS DE LAS FRONTERAS}

En Brasil, el debate sobre la integración de las mujeres del país en el mercado transnacional del sexo está marcado por la percepción, ya émica, de que la construcción de la femineidad nacional, sexualizada y marcada por el "color", es un aspecto central en diferentes dinámicas de consumo de sexo permeadas por la desigualdad: en el "turismo sexual internacional", en la prostitución de brasileñas en el exterior y en la trata de mujeres (Cecria 2000). El supuesto es que esa construcción, originada en las imágenes de mulatas y negras producidas 
en el Brasil y difundidas en el exterior, explica la elevada demanda de brasileñas. Esas imágenes, asociadas a trazos fenotípicos vinculados a mujeres de piel oscura, como los que constituyen la figura de la mulata (Corrêa 1996), se habrían difundido en el exterior donde las brasileñas se convirtieron en exóticos productos de consumo.

Esa explicación, en la que la "raza" es sexualizada, mantiene relaciones con la percepción de cómo, históricamente, fue creada y diseminada esa noción acerca de la femineidad brasileña. Pensadores sociales nacionales y también extranjeros consideran que una apreciación sexualizada de la brasileñidad es parte de los valores en términos de los cuales los brasileños se perciben. La idea es que esta construcción está basada en la literatura científica y de viajes de europeos que visitaron el país desde el siglo XVIII (Heilborn y Barbosa 2003; Parker 1991).

Nociones presentes en esos escritos, recreadas en diferentes períodos históricos, habrían sido incorporadas por la población nativa, inclusive por estudiosos que discutieron la constitución de la nación en la década de 1930 (Rago 1998). En las articulaciones entre raza y género que marcan la actualización de esas nociones, la imagen de la mulata construida como objeto de deseo y símbolo nacional aparece como síntesis de la percepción sexualizada de la brasileñidad (Moutinho 2004; Corrêa 1996).

En décadas recientes, las construcciones sobre el Brasil producidas en el país fueron difundidas al exterior. Las propagandas oficiales de agencias gubernamentales, como Embratur, responsable por la regulación del turismo, ofrecen un ejemplo. Entre 1970 y 1980, esa agencia eligió a las mulatas, conjuntamente con las playas de Rio de Janeiro y el samba, para estructurar la imagen de Brasil en el mercado turístico internacional (Alfonso 2006).

La idea de que las convenciones de erotismo producidas históricamente en el Brasil fueron exportadas y asimiladas linealmente en el exterior presenta, sin embargo, algunos problemas. Uno de ellos es pensar que las marcas de identidad vinculadas a la brasileñidad que se difunden a través de las fronteras necesariamente reiteran aquellas producidas en el Brasil. Luciana Pontes (2004) ofrece un sugestivo contrapunto mostrando cómo, en las imágenes que circulan en Portugal, las brasileñas, independientemente de su color de piel, son tratadas como mestizas porque su nacionalidad ya les confiere esa filiación. En ese país, esas representaciones tienden a ser erotizadas por medio de una construcción de nacionalidad que es sexualizada, pero que no necesariamente está asociada a los "colores" de piel oscura (Pontes 2004).

Un segundo problema es que los significados atribuidos a la "etnicidad" difieren en distintos contextos migratorios. En este sentido, vale recordar la observación de Igor Machado (2003), llamando la atención sobre la existencia de procesos de exotización diferenciados en las distintas sociedades de recepción de los migrantes. Comprender la circulación de imágenes vinculadas a 
trazos "étnicos" requiere prestar atención a la articulación de flujos, múltiples y simultáneos, de ideas diferentes en contextos específicos.

\section{ESCENARIOS}

La migración brasileña en Italia y España no es particularmente relevante en términos numéricos cuando se la compara con la de ciudadanos de otras naciones latinoamericanas. Sin embargo, en ambos adquiere aspectos significativos. En los dos, la comunidad de brasileños creció a un ritmo intenso a partir de la mitad de la década del 2000 y está marcada por el predominio de mujeres (Bogus y Beozzo Bassanezi 2001; INE 2006). En ambos, las brasileñas son consideradas un contingente relevante en las ocupaciones de limpieza y cuidado y en la industria del sexo y también integran los principales colectivos nacionales extranjeros proveedores de esposas para los hombres nativos (Piscitelli 2008a, 2007). Observo que, en el Sur de Europa, esa conjunción no se restringe a esos dos países. Está presente también en Portugal, donde diferentes estudios muestran el lugar significativo ocupado por las brasileñas en la industria del sexo (Ribeiro et al. 2005) y en el mercado matrimonial (Togni 2008).

En Italia, como en otros países de Europa, se considera que a partir de la década de 1990 hubo un aumento sustancial de extranjeras que ofrecen servicios sexuales. Según los estudios sobre el tema, las prostitutas extranjeras, conjuntamente con bailarinas eróticas y esposas encargadas por correspondencia, inundaron la industria del sexo, diversificando la "oferta" y estimulando el consumo de prostitución por parte de clientes de diversas franjas de edad (Leonini 1999). De acuerdo con esas investigaciones, en los primeros años de la década de 2000 parte significativa de esa actividad era desarrollada por transexuales y mujeres latinoamericanas, africanas y del Este de Europa. Las brasileñas desempeñarían sus actividades predominantemente en espacios cerrados, a los que acuden clientes de estratos sociales medios (Ambrosini 2002; Campani 1998).

Al mismo tiempo, los análisis de las migraciones observan que la práctica de contraer matrimonio con personas extranjeras ha aumentado en Italia. En 2000, los casamientos "mixtos", entre personas nacidas en Italia y en el exterior, representaron 7,1\% del total. La mayor parte de esas parejas estaba compuesta por hombres italianos y mujeres extranjeras. En la mitad de la década de 2000, Brasil aparece como el principal proveedor de esposas latinoamericanas (ORIM 2003; INS 2005).

Este es el marco en el que se insertaron las brasileñas que partieron de los circuitos de "turismo sexual" en Fortaleza. Ellas viajaron a través de las relaciones con turistas extranjeros que conocieron en la ciudad. Entre esas jóvenes, el patrón migratorio es semejante. Trabajaban en los espacios turísticos, estableciendo sucesivas relaciones con extranjeros con el objetivo de mejorar de vida y, frecuentemente, también con el fin de viajar al exterior. 
Después de dejar el Brasil, algunas, en un tránsito estacional entre Milán y Fortaleza, permanecían durante algunos meses en Italia, buscando clientes que conocieron en Brasil, regresando a casa con dinero, para retornar posteriormente a trabajar en Italia. Otras, reiterando el patrón "artesanal" característico del "turismo sexual" en Fortaleza, visitaban a sus "novios"/clientes en Italia, buscando alguna posibilidad de permanecer en el país a través de ellos. Cuando no lo lograban, volvían a Brasil trayendo consigo valijas repletas y retornaban a los circuitos de "turismo sexual" en Fortaleza, procurando un nuevo novio extranjero que viabilizase otra partida al exterior.

La mayor parte de las entrevistadas, no obstante, permaneció en Italia y se casó con italianos que conocieron en Fortaleza, dando lugar a casamientos que podrían ser integrados en la categoría de marriage migration, en que mujeres del "Tercer Mundo" se desplazan para casarse con hombres de países del Norte (Roca i Girona 2007; Puerta y Masdeu 2007). Entre estas últimas, ninguna trabaja hoy como prostituta. Pasaron un tiempo en situación migratoria irregular antes del matrimonio pero en la época de la entrevista todas tenían residencia legal, obtenida mediante el casamiento, y algunas ya estaban trabajando en otros sectores de actividad.

Investigadores/as y agentes que trabajan en entidades que atienden trabajadoras/es del sexo consideran que en España el perfil de la prostitución, así como el de la ocupación en otros sectores, como el servicio doméstico y la agricultura, también se modificó a partir de la década de 1990, pasando a contar con una presencia importante de personas extranjeras (Pons 2003; Agustín 2005). Diversos informes de investigación señalan que la presencia de latinoamericanas es significativa, particularmente en algunas regiones de España, y observan que las mujeres brasileñas están sobre todo en espacios cerrados. Son pisos y clubes que concentran chicas de Europa del Este (rusas, rumanas, de la antigua Yugoslavia, checas) y latinoamericanas. En esos espacios sería menor la presencia de africanas, nítidamente desvalorizadas. Paralelamente, en la mitad de la década de 2000, en el marco del aumento de casamientos "mixtos" entre españoles y extranjeras, las esposas brasileñas ocuparon un lugar particularmente destacado (INE 2006; Badet Souza 2009).

Las mujeres que entrevisté en España ya habían trabajado en la industria del sexo en Brasil. Algunas lo hicieron de manera intermitente y otras, "profesionales", vivieron exclusivamente de la prostitución antes de migrar a Europa. Sólo tres partieron de contextos de "turismo sexual", en Natal, Salvador y Rio de Janeiro. Las restantes ofrecieron servicios sexuales en otras ciudades brasileñas, principalmente en las regiones Sudeste y Sur del Brasil. El objetivo de la mayoría fue migrar para trabajar en la industria del sexo en España, considerando que obtendrían mayores ingresos que en Brasil. Apenas una viajó con el fin de trabajar en el servicio doméstico y, decepcionada con sus ingresos, optó por ofrecer servicios sexuales, algo que ya había realizado ocasionalmente 
en Brasil. Una pequeña parte de estas mujeres (cuatro) se casó con españoles, principalmente hombres que conocieron como clientes. Mientras la mayoría luchaba por la obtención de "papeles", las que se casaron obtuvieron residencia legal mediante el matrimonio, pero en ningún caso se trató de casamientos "blancos" o comprados. Sólo una de ellas dejó de trabajar en la industria del sexo. Las restantes ofrecen servicios sexuales en la calle, clubes y pisos.

\section{CONFLUENCIAS}

Las entrevistadas que migraron a Europa, a pesar de su heterogeneidad, comparten algunas características. Son mujeres heterosexuales, predominantemente jóvenes, en la faja de los veinte y treinta años, pero cuatro entrevistadas tienen más de cuarenta. Para mi sorpresa, descubrí que mujeres que consideraban que la edad redundaba en un menor valor de sus servicios en la industria del sexo en Brasil encontraron un mercado para su trabajo, en la calle, en España. El tiempo de residencia en uno u otro país europeo oscila entre uno y diez años.

Ellas no dejaron parejas en Brasil, pero tres de esas mujeres dejaron hijos y cuatro tuvieron hijos en el exterior, con parejas extranjeras. La mayoría cuenta con estudios secundarios incompletos o completos y una de ellas inició estudios universitarios que no llegó a concluir, lo que significa que tienen más años de estudio que la media de la población brasileña. En términos de las clasificaciones raciales imperantes en Brasil, sólo dos se auto-clasifican como mulatas o morenas oscuras. Sin embargo, todas consideran que los criterios raciales en el exterior son diferentes, marcando también a las que son consideradas blancas en Brasil.

Al dejar su país de origen, la mayor parte integraba los sectores más bajos de los estratos medios y dos formaban parte de clases sociales inferiores. Los factores económicos son centrales en la conformación de los proyectos migratorios. No obstante, esto no significa necesariamente aludir a una condición miserable en Brasil. En los términos de una trabajadora sexual de São Paulo:

"Ellos [los españoles] tienen unos prejuicios del tipo 'todo brasileño que viene para acá está pasando hambre en Brasil'. Y no es verdad. Si una persona viene para acá, eso ya exige un gasto. Si la persona está pasando hambre en Brasil, no puede pagar. Para venir hay que tener condiciones mínimas".

Para la mayoría se trata, sobre todo, de que sienten que no tienen posibilidades de trazar un futuro, para ellas y sus familias. Las palabras de una de las mujeres entrevistadas en España, de Belo Horizonte, sintetizan la percepción de la mayoría: 
“¿Salir de mi país para trabajar para comer? Comida tengo en mi país. No preciso estar lejos de mi familia para comer. En Brasil si plantas una mandioca, crías una gallina, comes. No es hambre. Es tratar de hacer algo..."

Finalmente, observo que ninguna de esas entrevistadas estaba en situación de trata, a pesar de que dos de las que viajaron en el objetivo de realizar servicios sexuales en España lo hicieron contrayendo deudas con propietarios de clubes, que saldaron en algunos meses.

\section{NOCIONES ITINERANTES}

En los procesos migratorios, las mujeres de los países del Sur no integran un contingente homogéneo. Sin embargo, tienden a estar confinadas en algunas categorías ocupacionales. En el marco de las relaciones desiguales entre Norte y Sur, las diferencias entre ellas son producidas frecuentemente mediante la atribución de cualidades que evocan fronteras etno-sexuales, trazadas en las “interacciones" entre nociones de sexualidad y etnicidad (Nagel 2003). Esas fronteras forman parte de la delimitación de los nichos ocupacionales para las migrantes que varían en diferentes países. Tailandia todavía es uno de los principales destinos de "turismo sexual". Sin embargo, en Milán las tailandesas están asociadas, sobre todo, al trabajo en la limpieza.

En los flujos para España e Italia, las brasileñas tienden a ser marcadas con algunos atributos: un carácter abierto, una disposición alegre y natural hacia el sexo y una propensión igualmente naturalizada para el cuidado, la domesticidad y la maternidad. Esas cualidades expresan, a través de la articulación entre género, nacionalidad/etnicidad y sexualidad, el lugar subalterno concedido al Brasil en las relaciones transnacionales. Y esa articulación de diferencias tiende a ser racializada en términos etnicidad/nacionalidad, exceptuando los casos en que se trata de personas consideradas negras.

En esos países, la mayoría de las migrantes brasileñas no ha tenido ninguna vinculación con la industria del sexo. Sin embargo, esa articulación entre marcadores de diferencia sexualiza al conjunto de las brasileñas, incluyendo mujeres que se tornan empresarias, trabajan como profesionales liberales o son estudiantes de post-grado en los países de destino. Entre ellas, sólo las que obtienen mejores posiciones sociales en los países receptores, que suelen estar vinculadas a niveles superiores de escolaridad, y no son consideradas negras, son relativamente menos afectadas por esas nociones de brasileñidad.

La relación que ellas establecen con la articulación entre diferencias que las marca es inestable (Piscitelli 2010), como sucede con migrantes brasileñas que trabajan en diferentes sectores de actividad en otros países del Norte. Hay movimientos de resistencia y rechazo pero, situacionalmente, también de afirmación, cuando ellas "usan” algunos aspectos de las imágenes sobre ellas 
para negociar sus posicionamientos en los contextos migratorios (Togni 2008; Piscitelli 2008a)..$^{8}$

La pregunta aquí es icuáles son las "cualidades" activadas por las brasileñas que, partiendo de sectores del mercado del sexo en Brasil, en los que la sexualización es una herramienta para negociar sus posicionamientos, circulan en escenarios en los que las nociones relativas a la brasileñidad presentan algunos aspectos en común, pero también adquieren matices diferenciados?

\section{CONSIDERACIÓN Y RESPETO}

En el momento en que fue realizada la fase de la investigación en Italia, Brasil estaba adquiriendo visibilidad, perceptible en los festivales de música y en el comercio, en la osadía de la moda de playa, la ropa íntima y los estilos de depilación. Los brasileños eran populares en diversos servicios involucrando la corporalidad y en Milán una diversidad de restaurantes "étnicos" con música y, ocasionalmente, shows de mulatas, atraían a la clientela local. En ese marco, la brasileñidad, marcada por el género, incidía en una asociación entre mujeres brasileñas, disponibilidad sexual y, con frecuencia, prostitución. Esta relación se tornaba particularmente intensa cuando se trataba de mujeres que ingresaron en Italia para visitar hombres que las conocieron en lugares asociados al "turismo sexual".

Algunas de las entrevistadas que migraron a Italia ofrecían servicios sexuales en Fortaleza. Otras tenían trabajos estables en el sector de servicios y, a pesar de mantener relaciones con extranjeros mediadas por la búsqueda de beneficios materiales, no consideraban que hacían "programas" (intercambio explícito de dinero por servicios sexuales). Los viajeros extranjeros apreciaban sus estilos de femineidad, vistos como alegres y cariñosos e intensamente sexuales. En el marco de viajes en busca de "autenticidad", entendida como propensión natural para el sexo, ellas eran sexualizadas a través de un proceso de racialización en el que la intensidad sexual era asociada al color "moreno". Y esas mujeres se "apropiaban" de los trazos que se les atribuía, corporificándolos. A partir de ellos negociaban su posición en esas relaciones y trataban de atravesar barreras locales raciales y de clase que consideran imposibles de trasponer sin los recursos materiales y simbólicos ofrecidos por los visitantes extranjeros.

En el desplazamiento a Italia, esas entrevistadas trataban de afirmar su especificidad como portadoras de un saber sexual especial, de manera análoga a como lo hacían en Brasil. En Italia, sin embargo, la auto-sexualización parecía operar a favor, sobre todo, de las mujeres que "visitaban" turistas/clientes que conocieron en Fortaleza, para realizar "programas" y/o buscando una invitación

8 Ver, por ejemplo, los atributos accionados por migrantes brasileñas para crear espacios de agencia en la integración en el trabajo doméstico en Boston (Assis 2004), en sectores académicos en Los Angeles (Beserra 2007) y en el servicio público en Lisboa (Pontes 2004). 
para permanecer en el país. Para las que se casaron en ese país y dejaron el mercado del sexo, la "sensualidad tropical" pasó a asumir un valor ambiguo.

En los circuitos de "turismo sexual" de Fortaleza, mercado del sexo y mercado matrimonial se superponen parcialmente. Un conjunto de aspectos favorece esa intersección. La ambigüedad que permea los encuentros sexuales confunde a muchos turistas extranjeros, particularmente a los que tienen menos experiencia, en términos de viajes a la ciudad. Y, cuando se trata abiertamente de “programas", los visitantes suelen atribuir el interés de las chicas por el dinero a una extremada necesidad económica, lo que incide en que no las consideren prostitutas "profesionales". Finalmente, algunos visitantes ven en esas mujeres atributos que consideran deseables para una esposa, temperamento cariñoso y disposición para el cuidado, condimentados por una sensualidad extremada. En ese marco, "obtener" una pareja brasileña en el mercado del sexo puede ser considerado como algo positivo. En los términos de una joven que estableció diversas relaciones transaccionales hasta encontrar el italiano con el que se casó, refiriéndose al período del noviazgo:

“Llegaba yo, una brasileña bronceada, de pelo ensortijado, de top y minifalda. A los hombres se les caía la baba!... A veces yo pensaba, 'ojalá que él no se enoje'. Pero él decía que no, ‘es bueno para mi ego’. Él se imagina así, 'mira, yo, con una brasileña bonitona, morenaza'. Eso es bueno para mi ego y para el ego de él".

Pero, en el desplazamiento a Italia y al casarse, ese entrelazamiento ocasiona tensiones en el marco de relaciones conyugales regidas por códigos en los que el erotismo pierde la centralidad absoluta, el sexo suele reducirse a relaciones semanales y la pareja se inserta en relaciones familiares más amplias. En este escenario, a la alegría, apertura y disponibilidad sexual se adiciona otro trazo atribuido a la brasileñidad: cierta disposición para engañar. El fantasma de la traición amenaza la afirmación de los estilos de masculinidad de los maridos italianos e incide en celos y vigilancia constante. Y el "color moreno", como marca de nacionalidad, torna a las entrevistadas blanco de racismo en el espacio público, particularmente en el ámbito laboral y, a veces, también en el ámbito de las relaciones familiares más amplias.

Esas migrantes dejaron el mercado del sexo para ocuparse de sus nuevas familias. Algunas trabajan en período parcial como cajeras de supermercado, secretarias en oficinas o sirviendo en bares, pero, en sus narrativas, la vida familiar adquiere un lugar central. Para ellas, construir espacios de agencia en el ámbito familiar depende de un juego delicado, que involucra re-crear algunos trazos que neutralizan la ambigüedad adquirida por la "sexualidad tropical", tiñendo la intimidad con pinceladas de domesticidad y con trazos de género "tradicionales". En ese procedimiento, la disposición para el sexo es 
englobada por la afectuosidad. En las palabras de una entrevistada: "A la brasileña, en general, le gusta hacer sexo porque es cariñosa por naturaleza". Al mismo tiempo, el cuidado extremado con el cuerpo es englobado en una idea más amplia de cuidado doméstico, al que se le concedía escasa atención en Brasil. En los términos de una ex chica de "programa”, mostrando con orgullo el estado impecable de su departamento y las flores multicolores que plantó en canteros en la terraza:

"La mujer brasileña, como yo pienso, es toda diferente. En el modo en que camina, en que se viste, que ve la vida. Porque en Europa las mujeres son todas hombres. [Les interesa] su trabajo, su independencia, su vida y pierden un poco la femineidad... Eso es lo que ellos buscan en las brasileñas. Aquella cosa de ser mujer, a las brasileñas les gusta arreglarse el pelo, hacerse las uñas, cuidar de la casa".

La valorización de la maternidad, que adquiere un lugar destacado en los relatos, es uno de los principales puntos de coincidencia entre las entrevistadas, sus maridos y las familias de ellos. Y el amor, que en la mayor parte de los casos había sido considerado apenas una actuación útil para seducir a los novios/clientes en Brasil, pasa a ser traducido en términos tradicionales, usuales en generaciones anteriores en el Nordeste del Brasil, como consideración, respeto, aquel amor que se desarrolla después del casamiento, y que involucra gratitud y lealtad (Rebhun 2007). En los términos de una de esas entrevistadas:

"No puedo decir que estoy enamorada, pero respeto a mi marido. Prefiero divorciarme a traicionarlo... Él me envió pasaje, dinero... Yo le decía que no gustaba de él y que iba a volver a Brasil. Él lloraba, me decía que esperase, tuvo mucha paciencia. Eso fue conquistándome. El primer mes estuve muy deprimida. Después, con el casamiento, las cosas mejoraron. Y la luna de miel! Aquel lugar, las islas Maurício, es maravilloso! El agua llega a las cabañas... Él prometió que enviaría dinero a mi hija en el Brasil todos los meses y no falla nunca, envía dinero siempre el día 15... Estamos pensando en comprar un departamento el año próximo. Aquí tenemos una buena vida. Él es muy bueno conmigo. Y cuando tengo aquellos problemas con mi suegra, que me vuelven loca, él trata de equilibrar... Si lloro, él también llora, hace cualquier cosa para calmarme".

\section{PERFORMANCES DE CARIÑO}

Cuando inicié la fase de la etnografía realizada en España, la visibilidad del Brasil y la integración de la brasileñidad en las convenciones eróticas aparecía 
de manera más diluida que en Italia. Tomando como referencia Milán y Barcelona, la incidencia del Brasil en diversos aspectos, inclusive en los servicios corporales en sentido amplio, clases de baile y capoeira, samba-terapias, era más intensa en la ciudad italiana. Ese cuadro está en proceso de modificación. El crecimiento en el número de inmigrantes brasileños/as, la creación de organizaciones comunitarias y la realización frecuente de festivales culturales, abarcando música, danza, cine y exposiciones de arte están dando mayor visibilidad a esa nacionalidad en España.

Paralelamente, investigaciones recientes observan que los medios están contribuyendo en difundir una imagen de la brasileñidad marcada por género y sexualizada. En 2008, las televisiones españolas difundieron noticias en las que Brasil adquiría protagonismo entre los países de inmigración, particularmente en relación a los otros países de América Latina. Y las noticias presentaron una particularidad. Diferentemente de las noticias sobre migrantes de otros países que, cuando estaban marcadas por género, se referían básicamente a hombres, las noticias sobre el Brasil aludían a mujeres y estaban relacionadas a tres temas: prostitución, violencia de género y actos delictivos. En lo que se refiere a la prostitución, Brasil encabezó una lista en la que fue seguido por Rusia, Rumania y Colombia (Badet Souza 2009).

Las narrativas de las brasileñas entrevistadas en España están situadas en este cuadro de transformaciones. Mientras en Lombardía, en Italia, las brasileñas aparecen singularizadas por la vinculación con una sexualización intensa y racializada, que se materializa en el color "moreno", en Cataluña, las brasileñas tienden a diluirse en una categoría regional, como latinoamericanas. En lo que se refiere a la industria del sexo, la sexualidad tropical, racializada como "morena" no las excluye, pero es frecuentemente asociada a mujeres de las antiguas colonias españolas, entre las que se destacan, según los nichos de prostitución, las colombianas y cubanas. La competencia con ellas es registrada en las palabras de una joven trabajadora sexual que ofreció servicios en Andalucía y en Cataluña:

"No hay muchas cubanas, pero hay... Tenemos mucho en común las brasileñas y las cubanas, la religión... es la misma, eso de bailar, somos muy parecidas. Pero claro, en el piso, a ver, las cubanas son tan calientes cuanto las brasileñas, entonces [risas] la competencia... más aún que [con] las colombianas, yo creo que por eso no hay mucha amistad..."

Esa disputa por clientes, comentada en los estudios sobre el tema en España, es considerada "feroz" (Oso Casas y Ulloa Jiménez 2001). Según Pons (2003), en Cataluña los empresarios clasifican a las trabajadoras en base a nociones que atribuyen a latinoamericanas y africanas "el sexo a flor de la piel" y, por lo tanto, las perciben con una predisposición natural hacia él. Esto no 
sucedería con las mujeres del Este de Europa, consideradas más cultas y de más categoría. En un ranking organizado en base a juventud, belleza, educación y nacionalidad, las españolas encabezarían la jerarquía, seguidas por mujeres del Este Europeo, latinoamericanas y, en último lugar, africanas (Pons, Rodríguez e Vega 2002).

En ese escenario, permeado por una lógica que exige diversidad y novedad, propietarios de clubes y pisos eligen a las trabajadoras sexuales buscando variedad en las nacionalidades y estilos corporales considerados atrayentes y evitando los extremos, representados en su percepción por mujeres negras y, más recientemente, por “orientales”. En esos espacios las brasileñas no son privilegiadas, pero son incluidas en el abanico de nacionalidades que, entre las latinoamericanas, tienen "salida" en el mercado.

Los criterios de los clientes entrevistados no son coincidentes con los de los empresarios. No obstante, ellos tampoco prefieren a las brasileñas. La heterogeneidad de los consumidores de sexo en España, en lo que se refiere a trazos regionales, edad, clase social, escolaridad, nivel de ingreso y origen impide realizar generalizaciones sobre ellos. Sin embargo, relatos de clientes españoles de estratos medios en grandes ciudades, usuarios de clubes y de pisos con diferentes intereses en la industria del sexo, muestran la relativa irrelevancia de la nacionalidad. Esto es evidente entre los que conceden más importancia a la variedad sobre la singularidad y también entre los que procuran "naturalidad" y cuidado/cariño en la prestación de servicios sexuales. De acuerdo con clientes que, en Barcelona y Madrid, frecuentan clubes y pisos:

"Voy siempre al mismo lugar... Allí hay de todos los colores... rusas, belgas o rumanas, y rubias hasta negras... Lo que menos hay... son españolas... [He estado]... seguro, con una rumana, una rusa, albanesa, ecuatoriana, de Bolivia, de Venezuela, morenas así son estas chicas, brasileña, argentina... son todas iguales, al final es todo igual”.

"Hay chicas estupendas... Las últimas veces que he ido... había muchas del Este, que para mí, son las que están más a disgusto... Son de Rusia, Rumania, blanquitas... Como las elijo, eso ni lo sé yo... me gustan hermosotas, grandotas, una mujer que tenga carne... Elijo morenas, con ojos oscuros, puede ser hasta marroquí. Esto de los países, yo no soy así. Me gustan ellas como personas, claro, en la cama tiene que estar bien... Pero es el trato que te da. Y que a ella le guste... Las latinoamericanas, he estado con brasileña, venezolana, dominicana. Son diferentes de las mujeres europeas, de las marroquíes. Son mucho más naturales a la hora de afrontar la relación entre hombre y mujer, más abiertas, más simpáticas, creo que la cultura es así, el trato es más agradable". 
"Yo no soy alguien que se sienta atraído por la diversidad racial o geográfica... Conozco una persona y si... me cae bien, no estoy a ver cuál es el penúltimo grupo de mujeres de procedencia exótica que llega a la calle... Las... latinoamericanas tienen un carácter personal y una cultura sexual diferente de las africanas y de las mujeres de otros países de Europa... Tienen una forma de vivir la sexualidad más cariñosa, más contacto con la piel... Quizás las mujeres africanas sean un poco la antítesis... Y las mujeres del Este Europeo estarían en el medio, tipo, a veces frío, un sexo de poca caricia, poca ternura..."

Estos relatos muestran la existencia de estereotipos regionales en relación con la sexualidad, pero también que no se privilegia ninguna nacionalidad, y muestran la utilización de posibilidades abiertas por el mercado. Los clientes "aprovechan" la diversidad ofrecida para encontrar relaciones sexuales que, a pesar de comerciales, sean íntimas y cariñosas.

¿Cuáles son las marcas de identidad afirmadas por las trabajadoras del sexo brasileñas en este escenario? Ellas tratan de afirmarse en el mercado como brasileñas. En ese intento, ellas subrayan los mismos atributos. Ser "caliente" y, en algunos casos, "morena”, forma parte de ellos, pero las cualidades más destacadas, englobantes, son la alegría, el cariño y el cuidado con los clientes. En los términos de dos hermanas de Rio Grande do Sul, en la faja de los 30 años, rubias, en un club en Bilbao:

“¿Las nacionalidades más comunes en los clubes, aquí? Colombianas y brasileñas. Los hombres nos prefieren porque somos más cariñosas, nos preocupamos más por ellos y también somos más naturales... Las colombianas, usan tacos altísimos, mucho maquillaje y solo están interesadas en el dinero, solo quieren sacarle dinero a los clientes".

De acuerdo con una brasileña con piel del color de chocolate, que se considera mulata, de cabellos larguísimos, dorados, con rulos, de 38 años en la época de la entrevista, trabajadora sexual en la calle, en Barcelona, reflexionando sobre "color" de la piel y racismo en España:

"Aquí, el racismo es diferente que en Brasil. No está asociado al color, sino a la nacionalidad. Hay lugares en los que no entra ecuatoriano, no importa si es más claro o más oscuro, o moro. Ya si es brasileño, es más difícil que tenga problemas. Les gusta el Brasil, Ronaldinho, Carlinhos Brown. A ellos les gustan las morenas. Pero lo que más les gusta de mí, como de otras brasileñas, es que soy cariñosa y alegre".

Otras entrevistadas añaden al cariño la propensión para la higiene, el ser muy limpias. De manera aparentemente paradójica, ninguna de esas trabajadoras 
sexuales afirma ser portadora de un saber específico sobre el sexo o la realización de prácticas sexuales diferenciadas. De acuerdo con una mujer de 48 años, que se considera blanca, rubia y de ojos verdes, que trabaja en la calle, en Barcelona:

"[Las otras,] por ejemplo, dejan que el hombre goce en la boca de ellas, sin preservativo, no pasa nada. A los españoles les gustan mucho esas anarquías. Nosotras no lo hacemos. Pero está el otro lado, somos más cariñosas con los clientes".

El punto importante es que, en estos sectores altamente mercantilizados de la industria del sexo en España, los atributos que esas migrantes subrayan para afirmar su brasileñidad son la afectuosidad y el cuidado. En este escenario, la supuesta "superioridad" concedida a esta nacionalidad en virtud de una sexualidad exacerbada, asociada a un saber específico y vinculado a la valorización del color "moreno" se tornan secundarios. Las cualidades destacadas tienen cierto sabor a domesticidad. Accionándolas, las entrevistadas procuran posicionarse en un contexto marcado por la competencia por clientes entre mujeres de diversas nacionalidades.

Entre esas entrevistadas, pocas se casaron o mantienen relaciones amorosas estables en España. Entre ellas se delinean tres estilos de relaciones: el casamiento con un cliente, permaneciendo en el mercado del sexo con el conocimiento del marido; el casamiento con un hombre conocido trabajando en ese sector, que redunda en el abandono de esa actividad y el noviazgo, ocultando el trabajo como prostituta. Pero las cualidades que contribuyen con el posicionamiento de estas mujeres en la industria del sexo no necesariamente las auxilia en la apertura de espacios de agencia en el ámbito de esas relaciones.

Una de las pocas entrevistadas que afirma la compatibilidad entre el casamiento y el trabajo en la industria del sexo me invitó a almorzar en su casa de Barcelona un lunes, día libre para ella y para el marido, camarero de un bar. Él, hijo de andaluces, amable y alegre, preparaba aperitivos en la cocina. El piso, confortable, estaba muy limpio, organizado y repleto de fotografías de familia, la familia brasileña de ella y la familia española de él, colgadas en paredes opuestas. Mientras él trabajaba en la cocina bromeando: "¿has visto como ella me explota?", nosotras conversamos en la sala, sentadas en un sofá rosa Dior. Ella contaba que el trabajo había empeorado en Barcelona después de la crisis y, bajando la voz, me dijo que tenía ganas de probar suerte por un par de semanas, trabajando en la prostitución en Australia. Pero creía que él, que estaba de acuerdo con que mantuviera su trabajo, ya que acababa de pagar las tierras que compró en Brasil, no vería con buenos ojos ese nuevo viaje. Y ella no quería crear problemas: 
“¿Has visto cómo es? Es bueno. Estoy bien con él, no estoy enamorada... Pero la pasión, eso pasa. Él es bueno, alegre, bebe una cervecita y ya está, la gustan las fiestas, es compañero".

En las narrativas de esas mujeres, sin embargo, la armonía en las relaciones con clientes o con hombres que saben que ellas trabajan en el mercado del sexo es considerada inusual. En ese punto coinciden con observaciones presentes en otros estudios sobre el mercado del sexo en España (Oso Casas 2010). Los relatos de otras entrevistadas remiten a relaciones en las que la re-creación de cualidades vinculadas a la domesticidad no neutraliza el estigma que envuelve el trabajo sexual. En el relato angustiado de una brasileña, que dejó el trabajo en un club al casarse con un vasco, madre de dos niños pequeños:

“Él dice que nuestra relación no es normal, porque en una relación normal las personas se conocen en otro lugar y no en un club... Vive humillándome, me dice que soy asquerosa... Y yo aguantando... No me arrepiento de haber venido acá, de haber tenido mis hijos... de trabajar en el club tampoco. A veces me da una locura por volver, porque no hay trabajo en el que se gane ni la mitad. Me arrepiento de no ser más yo, de estar dependiendo de él..."

Las narrativas remiten a tensiones cotidianas en el ámbito de la intimidad, revestidas de nociones de "diferencia cultural" en un juego en el que en cuanto ellas afirman sus cualidades de limpieza corporal y temperamento cariñoso, sus parejas las inferiorizan alternativamente, como brasileñas o remitiendo a la categoría más englobante, sudamericanas. Una trabajadora sexual de São Paulo describió relaciones sucesivas que tuvo con novios con los que fue a vivir en los siguientes términos:

“El primero era un catalán y no funcionó. El sabía de mi trabajo. Salimos un mes y medio y me fui a vivir con él. Él no quería que continuase trabajando y dejé. Pero... en un mes me fui de su casa. Fue terrible... Los catalanes tienen una cultura así de ser avaros... El primer choque cultural fue en relación a la higiene. En Brasil nos bañamos dos veces por día y nos cepillamos los dientes tres veces por día... Aquí no. Se bañan y cepillan los dientes una vez por día y no usan hilo dental! Y eran unas peleas. Mi baño era de 20 minutos y el golpeaba la puerta: 'estás gastando agua y gas'!!!... Yo le decía que era un sucio... Aquí las personas son muy frías. Los brasileños son más cariñosos, si te gusta la persona, haces sexo un montón de veces y él no, solo una vez por semana. Tenía grandes prejuicios en relación al Brasil. Y en cualquier discusión salía que yo había sido prostituta. Cuando terminamos y volví a trabajar [en la prostitución] amenazó con denunciarme si no pagaba 
las cuotas de una moto que compró... Después tuve un novio alemán. Duró dos años... Con este dejé claro que no iba a parar de trabajar. Él nunca tocó en el asunto. Pero tuvimos una discusión porque él fue infiel... descubrí que el continuaba yendo a clubes [de prostitución]. Y ahí él me dijo: '¿Pero acaso tu no vas todos los días?' Y sexualmente, quería cosas que yo sé que con una novia normal, él no pediría, por ejemplo, estímulo anal... Un hombre, cuando sale con una mujer que trabaja en la prostitución, ya siente esa libertad. No veo eso tan negativo. Pero, después quiso otras cosas, ir a un lugar de intercambio [de parejas]. Y yo pensaba, ya hice eso cobrando, pero no tengo porqué hacerlo con un novio... Para él una sudamericana sólo podía trabajar en la limpieza o en la prostitución. Terminé la relación, pero sufrí mucho... Por eso, mi novio de ahora no sabe nada".

El conjunto de tránsitos a partir de diferentes sectores del mercado del sexo ofrece elementos para pensar en la mercantilización de la intimidad, en las tensiones que ella suscita y en las categorías de identidad accionadas en esos desplazamientos. La búsqueda de relaciones afectuosas, como de novios, en el mercado del sexo no es inusual en Brasil, particularmente en espacios "artesanales" de ese mercado. Las dinámicas presentes en lugares de "turismo sexual" son una re-creación, en escala transnacional, de una larga tradición de intercambios económicos y sexuales que involucran intimidad e inclusive domesticidad, en la que están inmersas mujeres de algunos sectores sociales.

La búsqueda de relaciones "cariñosas" por parte de clientes de la prostitución puede parecer contradictoria, particularmente cuando tiene lugar no en espacios confusos y ambiguos en el Tercer Mundo, sino en sectores altamente organizados y mercantilizados de la industria del sexo en países europeos. Los análisis sobre los significados concedidos al consumo de sexo en el mercado global del sexo contemporáneo contribuyen a comprender esa búsqueda. Elizabeth Bernstein (2007) argumenta que, en el marco de la globalización capitalista de finales del siglo XX e inicios del XXI, los intercambios sexuales comerciales pasan a ser regidos por nuevos códigos, en los que la re-creación de la intimidad y la performance emocional adquieren centralidad.

De acuerdo con Bernstein (2007), las transformaciones económicas de las décadas recientes reestructuraron la geografía social del trabajo sexual. En este proceso, los significados subjetivos presentes en las experiencias en el interior del mercado del sexo también se modificaron. En el marco de un paradigma de comercio sexual post-industrial, la autora identifica un nuevo estilo de prestaciones sexuales, que estaría difundiéndose entre consumidores de sexo de clase media, predominantemente blancos, que frecuentan espacios cerrados en algunas ciudades de países del Norte. Clientes que optan por el sexo comercial como actividad de ocio buscan intercambios que involucran más trabajo emocional y físico. El nuevo estilo estaría caracterizado por una serie de elementos 
que remiten a las relaciones emocionales: el sexo como novios, los besos en la boca, las conversaciones y los masajes, y la utilización de períodos de tiempo más prolongados.

Parte significativa de la nueva variedad de trabajo sexual residiría en ofrecer y consumir conexión emocional y física temporaria, pero con sabor a domesticidad, que evoca la idea de "afecto auténtico" y provoca en los clientes la sensación de ser deseados, estimados y también amados. Este tipo de transacción introduciría elementos de la vida erótica "privada" y emocional en el ámbito del sexo comercial. Bernstein (2007) argumenta que la interpenetración entre intimidad y comercio está transformando mutuamente el carácter de esos dominios. Y si en el pasado la sexualidad vinculada al romance, presente en relaciones que tenían lugar en el espacio doméstico, adquiría sentido en el marco de una oposición ideológica con el mercado, las nuevas modalidades de sexo comercial no presentarían antagonismos con la intimidad. Están disponibles para compra y venta como cualquier otra forma de actividad de ocio comercial.

Estos aspectos, próximos a las percepciones de los clientes españoles entrevistados, ayudan a pensar en los atributos corporificados por las entrevistadas, presentados como trazos "étnicos"/nacionales. En el escenario de la industria del sexo en España, en el que la singularidad nacional se diluye en estereotipos regionales y en el que clientes que frecuentan diversos nichos de prostitución procuran la ilusión de placer recíproco y "cariño", las entrevistadas destacan la "afectuosidad" y el cuidado como trazos centrales de la brasileñidad.

\section{CONSIDERACIONES FINALES: DESPLAZANDO SIGNIFICADOS}

En este texto mostré cómo las migraciones de brasileñas a partir de contextos del mercado del sexo accionan diversas marcas de identidad. En los procesos migratorios hacia los países del Sur de Europa, las imágenes de la brasileñidad no se mantienen estables. En esos desplazamientos, las convenciones asociadas a la nacionalidad son re-significadas de maneras diferenciadas por mujeres que ofrecen servicios sexuales o que, al contrario, abandonan ese sector de actividad mediante el casamiento, en países cuyas relaciones históricas con el Brasil son diferenciadas.

En esos tránsitos, entrevistadas habituadas en Brasil a negociar sus espacios de agencia corporificando la sexualización de la que eran objeto en el mercado del sexo y, en sus sectores transnacionales, la racialización que las singularizaba como "morenas/brasileñas", se enfrentan con la necesidad de adecuar sus "cualidades" a los criterios y atributos valorizados en cada escenario. Lo hacen destacando, por diferentes razones, trazos que, sin desdibujar la sensualidad, las vinculan a la domesticidad. Y, en el escenario español, en el que sus atributos se diluyen en la categorización englobante de latinoamericanas, hacen esfuerzos 
por "nacionalizar" los trazos requeridos en la industria del sexo, como herramienta para posicionarse en un mercado caracterizado por la competencia y la diversidad étnico/nacional.

Si la interpenetración entre intimidad y comercio transforma mutuamente el carácter de esos dominios, ese proceso no está libre de tensiones. En los escenarios contemplados, estas se revelan en la superposición entre mercado del sexo y del casamiento. La relativa imprecisión de fronteras en lo que se refiere a la elección de pareja parece sugerir modificaciones en el trazado de límites morales. Sin embargo, las narrativas sobre relaciones conyugales, amorosas y familiares muestran el esfuerzo constante realizado para delinear las cualidades morales apropiadas para ese tipo de intimidad. En los términos de Zelizer (2009), las relaciones de intimidad sexual implican a menudo transferencias de dinero, pero distintas clases de intimidad envuelven distintas cualidades morales. Esta idea contribuye a comprender la tensión constante suscitada por los procesos de sexualización que afectan a las entrevistadas que se casaron y el esfuerzo en términos de reconfiguración de categorías de identidad de las entrevistadas para neutralizarlas. Y contribuye a entender el éxito relativamente superior de esas reconfiguraciones, en el sentido de abrir espacios de agencia, en relaciones que se iniciaron en sectores artesanales y ambiguos del mercado del sexo y en las que la superposición entre mercado del sexo y del casamiento, temporaria, se limita al momento de selección de cónyuge.

\section{BIBLIOGRAFÍA}

AgUSTín, Laura, 2005, Trabajar en la Industria del Sexo, y Otros Tópicos Migratorios. San Sebastián, Tercera Prensa.

ALFONSO, Louise Prado, 2006, Embratur: Formadora de Imagens da Nação Brasileira. Campinas, Universidade Estadual de Campinas, tesina de maestría.

Ambrosini, Maurizio, 2002, Comprate e Vendute: Una Ricerca su Tratta e Sfruttamento di Donne Straniere nel Mercato della Prostituzione. Milán, Caritas Ambrosiana/Franco Angeli.

ASSIS, Gláucia de Oliveira, 2004, De Criciúma para o Mundo: Rearranjos Familiares e de Gênero nas Vivências dos Novos Migrantes Brasileiros. Campinas, Unicamp, tesis de doctorado.

BADET SOUZA, Maria, 2009, Televisión y Construcción del Imaginario de la Mujer Brasileña en

España: Propuesta de Una Metodología de Análisis Multidimensional. Barcelona, Universitat Autónoma de Barcelona, tesina de maestría.

BERNSTEIN, Elizabeth, 2007, Temporarily Yours: Intimacy, Authenticity and the Commerce of Sex. Chicago, The University of Chicago Press. 
BESERRA, Bernadete, 2007, "Sob a sombra de Carmen Miranda e do carnaval: brasileiras em Los Angeles", Cadernos Pagu, 38: 313-344.

BOGUS, Lucia Maria Machado, y Maria Silvia BEOZZO BASSANEZI, 2001, "Brasileiros/as na Itália: nuovi cittadini ou extracomunitari?”, en Mary Garcia Castro (coord.), Migrações Internacionais: Contribuições para Políticas. Brasília, Comissão Nacional de População e Desenvolvimento, 409-427.

CAMPANI, Giovanna, 1998, "Trafficking for sexual exploitation and the sex business in the new context of international migration: the case of Italy", South European Society and Politics, 3 (3): 230-261.

CECRIA, 2000, "Tráfico de Mulheres, Crianças e Adolescentes para Fins de Exploração Sexual no Brasil: Projeto de Pesquisa”. Brasília, UnB.

CLIFFORD, James, 1997, Routes, Travel and Translation in the Late Twentieth Century. Cambridge, Harvard University Press.

CONSTABLE, Nicole, 2009, “The commodification of intimacy: marriage, sex and reproductive labour", Annual Review of Anthropology, 38: 49-64.

CORRÊA, Mariza, 1996, "A invenção da mulata", Cadernos Pagu, 6-7: 25-50.

DESROISÈRES, Alain, 1978, "Marché matrimonial et structure des classes sociales", Actes de la Recherche em Sciences Sociales, 21: 97-107.

HEILBORN, Maria Luisa, y Regina BARBOSA, 2003, "Sexuality research training in Brazil", en Diane Mauro, Gilbert Herdt y Richard Parker (eds.), Handbook of Sexuality Research Training Initiatives. New York, Social Science Research Council.

HOCHSHILD, Arlie Russell, 2003, The Commercialization of Intimate Life. Berkeley, The University of California Press.

HUNTER, Mark, 2002, “The materiality of everyday sex: thinking beyond 'prostitution'”, African Studies, 61: 99-120.

INE, 2006, Base de datos INEbase, Instituto Nacional de Estadística (España), disponible en <www.ine.es> (acceso en 17-07-2007).

INS, 2005, Gli Stranieri in Italia: Analisi dei Dati Censuari, Istituto Nazionale de Statistica (Italia), disponible en <www.istat.it> (acceso en 23-01-2007).

KEMPADOO, Kamala, 2004, Sexing the Caribbean: Gender, Race and Sexual Labour. Abingdon, Routledge.

LEONINI, Luisa, 1999, Sesso in Acquisto: Una Ricerca sui Clienti della Prostituzione. Milán, Unicopli.

MACHADO, Igor José de Renó, 2003, Cárcere Público: Processos de Exotização entre Imigrantes Brasileiros no Porto, Portugal. Campinas, Unicamp, tesis de doctorado.

MARCUS, George, 1995, "Ethnography in/of the world system: the emergence of multisited ethnography", Annual Review of Anthropology, 24: 95-1 17.

MOUTINHO, Laura, 2004, Razão, “Cor” e Desejo. São Paulo, EDUSC.

NAGEL, Joane, 2003, Race, Ethnicity, and Sexuality: Intimate Intersections, Forbidden Frontiers. New York, Oxford University Press.

ORIM, 2003, L'Immigrazione Straniera in Lombardia: La Seconda Indagine Regionale, Rapporto 2002. Milán, Osservatorio Regionale per l'Integrazione e la Multietnicitá y Fondazione ISMU.

OSO CASAS, Laura, 2010, "Money, sex, love and the family: economic and affective strategies of Latin American sex workers in Spain”, Journal of Ethnic and Migration Studies, 36 (1): 47-65. 
OSO CASAS, Laura, y Marcela ULLOA JIMÉNEZ, 2001, “Tráfico e inmigración femenina desde la voz de las mujeres inmigrantes”, en Elena Jáudenes Bonelli y Marcela Jiménez Ulloa (eds.), Tráfico e Inmigración de Mujeres en España, Colombianas y Ecuatorianas en los Servicios Domésticos y Sexuales, Madrid, ACSUR/Las Segovias, disponible en <www.acsur. org > (acceso en 24-01-2007).

PARKER, Richard, 1991, Corpos, Prazeres e Paixões: A Cultura Sexual no Brasil Contemporâneo. São Paulo, Best Seller.

PISCITELLI, Adriana, 2007, "Shifting boundaries: sex and money in the Northeast of Brazil", Sexualities, 10 (4): 489-500.

— 2008 a, "Comparative symposium: looking for new worlds: Brazilian women as international migrants”, Signs: Journal of Women in Culture and Society, 33 (4): 784-794.

—, 2008 b, "Sexo tropical em um país europeu: migração de brasileiras no marco do turismo sexual internacional”, Revista Estudos Feministas, 15 (3): 717-744.

— 2009 , "As fronteiras da transgressão, a demanda por brasileiras na indústria do sexo na Espanha", Sexualidad, Salud y Sociedad: Revista Latinoamericana, 1: 177-201, disponible en <http://www.e-publicacoes.uerj.br/ojs/index.php/SexualidadSaludySociedad > .

— 2010 , "Exportación de esposas? Casamientos de brasileñas como puerta para la migración a países europeos", texto presentado en el II Congreso Feminista Internacional, Buenos Aires.

PONS, Ignasi, 2003, Condicions de Treball en la Nova Indústria de la Prostitució: Els Clubs d'Alterne. Barcelona, Universitat de Barcelona.

PONS, Inaci, Roser RODRÍGUEZ, y Sonia VEGA, 2002, Trabajo Sexual: Informe Cataluña. Barcelona, Departamento de Sociología i Análisis de las Organizaciones, Universidad de Barcelona.

PONTES, Luciana, 2004, "Mulheres brasileiras na mídia portuguesa", Cadernos Pagu, 23: 229-257.

PUERTA, Yolanda Bodoque, y Montserrat Soronellas MASDEU, 2007, Matrimonios Transnacionales: Nuevos Retos en el Análisis de Una Realidad Migratoria Particular. Tarragona, Universidad de Tarragona.

RAGO, Margareth, 1998, "Sexualidade e identidade na historiografia brasileira", en Maria Andréa Loyola (ed.), A Sexualidade nas Ciências Humanas. Rio de Janeiro, UERJ, 175-200.

REBHUN, Linda-Anne, 2007, “The strange marriage of love and interest: economic change and emotional intimacy in Northeast Brasil”, en Mark Padilla, Jennifer Hirsh, Miguel Muñoz-Laboy, Robert Sember y Richard Parker (eds.), Love and Globalization: Transformations of Intimacy in the Contemporary World. Naschville, Vanderbilt University Press, 107-120.

RIBEIRO, Manuela, Manuel Carlos SILVA, Johanna Schouten PATUlEIA, Fernando Bessa RIBEIRO, y Octávio SACRAMENTO, 2005, Prostituição Feminina em Regióes de Fronteira: Actores, Estruturas e Processos, Relatório Final. Vila Real, Universidade de Trás-os-Montes e Alto Douro, inédito.

ROCA I GIRONA, Jordi, 2007, “Amores lejanos, amores posibles: la constitución de uniones sentimentales entre hombres españoles y mujeres brasileñas en el marco de las transformaciones de los sistemas de género y del amor en la post-modernidad". Presentado en ANPOCS, Caxambú.

TOGNI, Paula Christofoletti, 2008, Os Fluxos Matrimoniais Transnacionais entre Brasileiras e Portugueses: Gênero e Imigração. Lisboa, ISCTE, tesina de maestría. 
WEITZER, Ronald, 2000, Sex for Sale: Prostitution, Pornography and the Sex Industry. New York, Routledge.

ZELIZER, Viviana, 2009, La Negociación de la Intimidad. México, Fondo de Cultura Económica.

Performing Brazilianness? Displacements from the sex market - Adriana Piscitelli - Núcleo de Estudos de Gênero-PAGU/Unicamp, Brasil • pisci@uol.com.br

Considering the trajectories of Brazilian women who migrated to Europe from different sectors of the sex market, in this paper I consider the notions of Brazilianness that permeate these women's spaces for agency. The analysis is based on a multi-sited ethnography carried out in Brazil, Italy and Spain. I consider how shifting contexts have effects in the re-creation of identity markers that permeate their incorporation in South European sex and marriage markets. I reflect on this exploring how constructions of gender, nationality, ethnicity and "race" are activated in the interactions of those migrants. Finally, I consider the relationships among these ethnic constructions, the migratory contexts and the shifts in the meanings acquired by sex consumption in the contemporary global sex market.

KEYWORDS: sex market, marriage market, migration, gender, sexuality, ethnicity. 